\title{
Proposal for an intelligent digital teacher's textbook solution adapted to the Bachelor-Master-Doctorate system
}

\author{
Ulrich Hermann Semevo Boko, Bessan Melckior Degboe, Samuel Ouya, Gervais Mendy
} Laboratory LITA, Higher Polytechnic School, University Cheikh Anta Diop, Dakar, Senegal.

\begin{abstract}
This paper proposes an intelligent solution for course monitoring based on the use of a digital textbook coupled with an algorithm for verifying the conformity of the teaching content. The proposed solution allows to follow in real time the evolution of the courses and to alert the pedagogical managers in case of noncompliance with the syllabus.
\end{abstract}

In most sub-Saharan African countries engaged in the Bachelor-MasterDoctorate (BMD) reform, incessant strikes prevent teachers from completing the program. Also, there is no way for the teacher to know whether students have the necessary prerequisites. In addition, constraints related to agendas sometimes prevent the holding of pedagogical animation meetings.

To solve these problems, we propose the implementation of an intelligent digital teacher's textbook. The tool helps in the follow-up and the respect of the pedagogical objectives. It implements an algorithm to evaluate in real time the concordance between the courses given and the requirements of the syllabus. An SMS and e-mail alert system has also been set up to inform training actors in case of non-compliance with the syllabus.

The proposed solution contributes to the overall improvement of the quality of higher education in Saharan Africa.

Keywords: BMD reform; course monitoring; pedagogical animation; quality of education. 


\section{Introduction}

Since 2011, most French-speaking African states have undertaken reforms in higher education to better adapt their training to international standards. The focal point of these reforms has been the adoption of the BMD (Bachelor-Master-Doctorate) as an education system.

One of the principles of the BMD system requires that there be a set of Teaching Units (UE) to be validated in order to obtain a degree. Each UE is made up of a set of coherent course, called by EC, belonging to the same disciplinary field. Because of the complementary links between UEs and ECs, it is essential to have a good pedagogical animation.

In sub-Saharan Africa in general and in Senegal in particular, incessant strikes in primary, secondary and higher education prevent teachers from completing the program. This has a negative impact on the quality of education as demonstrated by authors (Sy, 2008) and (Sall, 2014). In addition, there is no quick and reliable way for the teacher to know whether students have the necessary prerequisites.

In its traditional paper form, the textbook that should play this role has some shortcomings: loss or damage, infrequent consultation by the students, almost non-existent use by teachers outside their own classes and non-participation in the reduction of paper consumption to minimize the negative impact of paper production on the environment.

The authors (General Direction Of School Education - France [DGESCO], 2010) and (Costa et al., 2015) make proposals on the digital textbook. This new approach has a positive impact on the internal organization of the institution, pedagogical engineering and on the organization of teachers. However, the proposed solutions do not allow pedagogical managers to automatically check in real time the conformity between the course given and the syllabus.

This paper aims to propose an intelligent solution for monitoring courses based on the use of a digital textbook coupled with an algorithm for automatic monitoring of lessons. The proposed solution allows to follow in real time the evolution of the courses and to alert the pedagogical managers in case of non-compliance with the syllabus.

The rest of this paper is organized as follows: Section 2 describes the state of the art, Section 3 describes our methodology of research, Section 4 presents our solution, Section 5 outlines the results obtained, Section 6 is reserved for discussion and Section 7 for conclusion. 


\section{Related works}

\subsection{The BMD System}

The BMD is a training system that includes an architecture of studies in 3 grades (Bachelor, Master, Doctorate), organization of training courses in semesters and in the UE, contents structured in pluri and transdisciplinary fields with diversified career paths.

The BMD system aims to allow the learner to build a path adapted to his possibilities and needs. In order to do so, the BMD requires that training courses be flexible and organized around capitalizable units.

The adoption of the BMD when it is well understood constitutes a real change of mentality, another vision of university education: it then provokes a profound renovation of the whole system, of the whole university life.

\subsection{The BMD in Sub-Saharan Africa}

The BMD reform in Europe is the result of a long process, which was not the case for most African Universities (Diarra, 2009). A study (Mignanwande \& Hounmenou, 2016) conducted among 690 people selected by a random and intentional method shows that the fundamental principles of the BMD system are not yet mastered and applied by the different actors of the University of Abomey-Calavi.

Another difficulty in the implementation of the BMD system is the pedagogical scenario that this reform requires. Indeed, the respect of the order of succession of the EC and the UE according to the prerequisites remains very problematic in university training as demonstrated by the authors of this study conducted at the University of Burundi (Hajayandi, 2020).

The pedagogical methods (essentially theoretical courses) and the massification in African higher education institutions generally constitute obstacles to any idea of professionalization. The author (Diarra, 2009) proposes the creation of institutional support mechanisms to conduct the reform with the mission of sensitizing, informing and training all university actors involved in the implementation of the BMD system.

Also, mastering the university calendar, another requirement of the BMD is not easy because of strikes and other recurring social movements. Authors (Diop, 2016) and (Lauwerier, 2016) have shown that poor working conditions, low salaries and the expectation of subsidies lead teachers to take union actions that have a negative impact on learning and program completeness. 


\subsection{Digitization of the teacher's textbook}

According to (DGESCO, 2010), the digital teacher's textbook is a valuable tool for teachers, educators, administrators, and teaching staff. Accessible via the Internet, the digital textbook is intended to help support teaching and learning activities. (DGESCO, 2010) reminds us that the class textbook, even if dematerialized, is an official document with legal value. It allows, in the event of a teacher's absence or transfer, to ensure a close continuity between the teacher's teaching and that of his substitute or successor. In practice, the class textbook must be easy to use, reflect the course of instruction and allow the progression of learning to be accurately monitored. However, the proposed solutions (DGESCO, 2010), (Costa et al., 2015) and (Maugard, 2013) do not fully address the challenges of BMD in sub-Saharan Africa. Also, they do not allow educational managers to automatically check in real time the conformity between the course and the syllabus.

\section{Methodology}

To prove the relevance of our approach, we conducted a survey among 13 teachers from 11 public and private universities in West, East and Central Africa (Senegal, Benin, Central African Republic, Gabon, Djibouti). All the interviewees are involved in Science, Technology, Engineering, and Mathematics (STEM) fields. Of the 13 who responded, 5 have less than 5 years of experience and 8 have been teaching for more than 5 years.

The data was collected using the Google Form tool. The results reveal that only $7.7 \%$ systematically organise a meeting between teachers from the same UE, compared to $76,2 \%$ who say they do not find the time to meet to discuss the objectives of the UE. Finally, 16,1\% participate in pedagogical animation sessions but only for a few UEs.

The results of this study confirm the hypothesis that the constraints related to agendas prevent the actors of the BMD system from holding sessions that are essential for a good pedagogical animation. These results have led us to make a proposal for an intelligent digital textbook to improve the quality of education in sub-Saharan Africa.

\section{Smart Digital Teacher's Textbook}

To facilitate the pedagogical follow-up and to solve the problem of lack of time in the organization of animation meetings, we propose Smart Digital Teacher's Textbook.

Smart Digital Teacher's Textbook is a $100 \%$ digital solution that not only allows you to follow in real time the evolution of each EC but also to ensure that the pedagogical objectives are respected and achieved. 
The proposed system includes an application developed from the Spring and Angular frameworks, coupled with a MySql database for data persistence.

\subsection{Architecture of the proposed solution}

The proposed solution as shown in Figure 1 is a web application based on a monolithic architecture. The choice of this architecture was motivated by the fact that we would like to have a solution that is simple to build, test and deploy. In terms of performance, the monolithic architecture offers better performance than modular approaches such as MicroService Architecture (MSA).

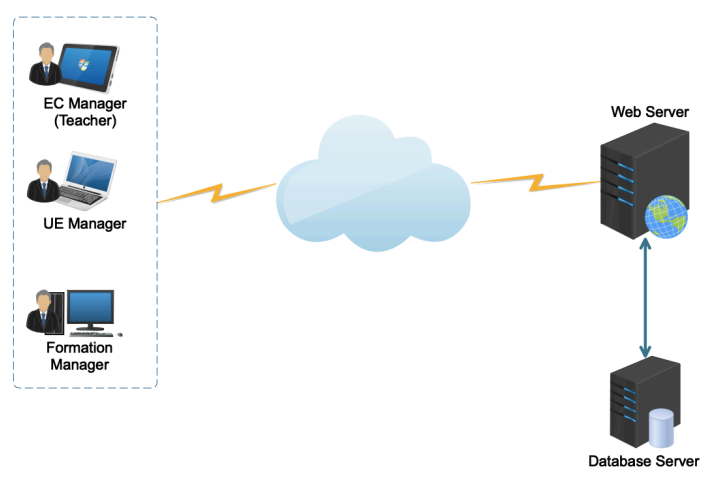

Figure 1. Architecture of the solution.

\subsection{Test environment}

The tests were carried out with the temporary teachers of the Bachelor 3, Master 1 and Master 2 classes of the Central School of Free Software and Telecommunications (EC2LT) in Dakar, Senegal. It should be noted that the teachers were not informed of the automatic conformity check carried out by the platform. To facilitate access to Smart Digital Teacher's Textbook, a link has been added to EC2LT's e-learning platform.

\section{Results}

We present here the use cases that allow the real-time monitoring of the evolution of each UE as well as the achievement of the pedagogical objectives.

\subsection{Case 1: The teacher (Head of EC) or the Student adds a new class session}

At the end of each class session, the teacher (responsible for the EC) or a student in the class has the possibility to add a new class session. To do so, he has the menu " My Courses " and a form for adding sessions. This form contains the fields " Date ", " Duration " and " Session content ". 
After adding or modifying a course session, a program is automatically launched to verify that the pedagogical objectives have been respected. This program performs a keyword analysis to determine if the content of the session is consistent with the EC objectives. Figure 2 summarizes the implemented algorithm.

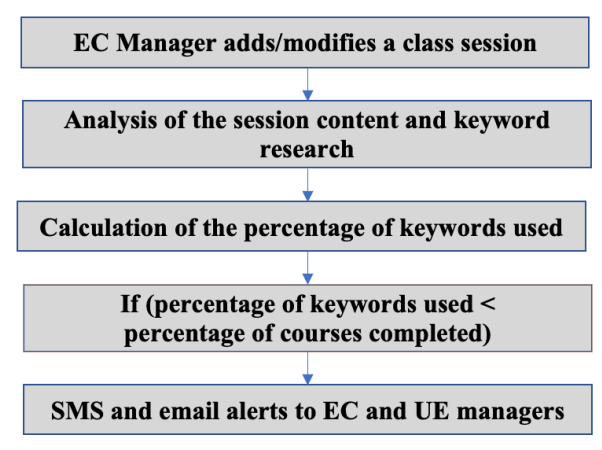

Figure 2. Algorithm of the solution.

\subsection{Case 2: The teacher (Head of EC) visualizes the ECs in his field of study}

The proposed solution allows the head of an EC to consult (read access only) the details of the sessions of all the ECs in the same disciplinary field. To do this, each EC manager has access to the "Global View" menu. This menu lists all the training courses and all the UEs in which the logged-in user intervenes. By choosing an EC, the user can then view the details (date, time and course content) of each session as shown in Figure 3.

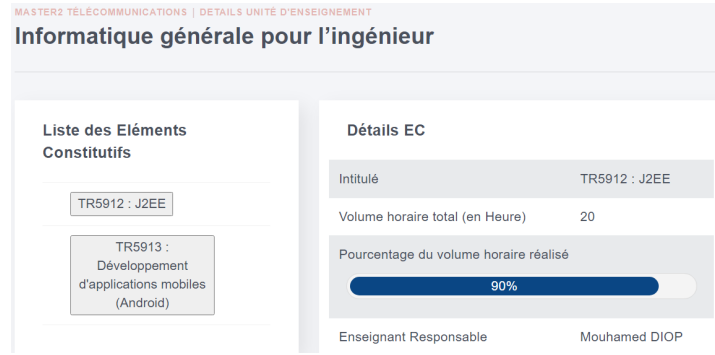

Figure 3. Detailed view of the EC for the teacher

\subsection{Case 3: The head of a teaching unit (UE) visualizes the progress of the ECs}

The head of a UE has full access to all the ECs in the Teaching Unit for which he is responsible. With the help of graphs, he has the possibility of following in real time the evolution of the ECs as well as the respect of the educational objectives. If necessary, can view the details (Title, Total hourly volume, percentage of courses completed, keywords and percentage of matching) of each EC. Note that keywords already used appear with a green tag as shown in Figure 4. 


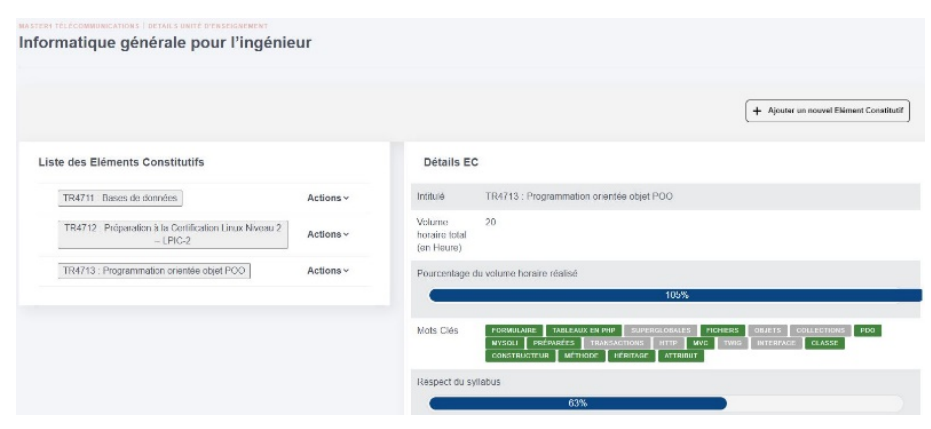

Figure 4. Detailed view of the EC for the head of the UE

\section{Discussions}

After having used the textbook for a full semester, we can affirm that Smart Digital TextBook brings a real added value to the pedagogical follow-up.

Unlike existing digital textbook solutions (DGESCO, 2010), (Costa et al., 2015) and (Maugard, 2013), Smart Digital Teacher's Textbook integrates an algorithm for automatic verification of course content and an alert system in case of non-compliance with the syllabus. It thus appears as a complete tool at the service of all the actors of the BMD system.

4 out of 10 EC managers have received alerts by sms and email to encourage them to comply with the recommendations of the syllabus. These alerts made it possible to immediately review the content of the next sessions with a view to achieving the pedagogical objectives. In addition, the pedagogical manager and the tuition department made use of the platform to ensure that the online courses were actually completed at the scheduled times. These training actors were also pleased to have a reliable tool for remote and real-time monitoring of the courses. However, it should be noted that despite the initial training of all teachers in the use of Smart Digital TextBook, the results show that those belonging to the "communication and general culture" disciplinary field have difficulty in appropriating this new tool. These difficulties are mainly related to the lack of mastery of the computer tool. This could constitute a brake on the generalization of the solution proposed in this article if no action is taken. Moreover, in the context of Covid19, Smart Digital TextBook limits the sharing of physical resources.

\section{Conclusion}

The results of this work show that digital can be used to contribute to the BMD maturation process in Sub-Saharan African countries. Smart Digital TextBook solves, among other things, the problems of pedagogical animation and course monitoring within universities. It also provides a solution to the problem of information sharing between teachers of the same 
disciplinary field and thus contributes to the overall improvement of the quality of teaching. The tests carried out reveal that initial training of teachers in the use of the solution is an essential prerequisite for its adoption. In perspective, we plan to integrate a synchronous communication space into the tool and improve the algorithm for keyword detection by introducing artificial intelligence.

\section{References}

Costa, P., Peraya, D., \& Rizza, C. (2015). L'usage du cahier de textes numérique dans l'enseignement secondaire français : un objet-frontière ? TICE et multiculturalités. Usages, publics et dispositifs, 201-216. Retrieved from https://archiveouverte.unige.ch/unige:78999.

Diarra, M. (2009). Le LMD et les écoles (africaines) en Science de l'Information: l'expérience de l'EBAD. World Library and Information Congress : 75th IFLA General Conference and Council. Retrieved from https://www.ifla.org/past-wlic/2009/86-diarrafr.pdf.

Diop, B. (2016). La réforme LMD au Sénégal: le point de vue des étudiants. Journal of HigherEducation in Africa, 14(2), 21-48. Retrieved from JSTOR. Retrieved from www.jstor.org/stable/90015345.

General Direction Of School Education - France [DGESCO]. (2010). Le cahier de textes numérique. NOR : MENE1020076C circulaire $n^{\circ}$ 2010-136 du 6-9-2010. Retrieved January 08, 2021, from http://www.education.gouv.fr/cid53060/mene1020076c.html.

Hajayandi, N. (2020). La réforme du système « Licence Master Doctorat » de l'enseignement supérieur au Burundi: enjeux et nouvelles exigences. The East African Review, 54. Retrieved from https://journals.openedition.org/eastafrica/1186.

Lauwerier, T. (2016). La contribution des enseignants à la pertinence de l'éducation de base en Afrique de l'Ouest: le cas du Sénégal. McGill Journal of Education, 51(2), 787-805. doi: 10.7202/1038603ar.

Maugard, E. (2013). L'impact de l'usage des cahiers de textes numériques sur les activités d'apprentissage hors des cours. Sciences et technologies de l'information et de la communication (STIC) en milieu éducatif. Retrived from https://edutice.archivesouvertes.fr/edutice-00875855.

Mignanwande, P. \& Hounmenou, J. (2016). The Three-Five-Eight (Bachelor, Master, Doctorate) System: An Essential and Demanding Reform for the University of AbomeyCalavi, Benin (West Africa). Open Journal of Social Sciences, 4, 158-170. doi: 10.4236/jss.2016.49014.

Sall, I., \& Sall, B. (2014). Au Sénégal, les progrès de l'éducation à la traîne malgré les investissements. Afro Baromètre Donner une voix au peuple, Note informative, 149. Retrieved from https://afrobarometer.org/publications/bp149-au-senegal-les-progres-eneducation-la-traine-malgre-les-investissements.

Sy, H. (2009). Grèves scolaires et universitaires au Sénégal Critique de la raison militante. Analele Ştiinţifice ale Universităţii» Alexandru Ioan Cuza «din Iaşi. Psihologie, (2), 7999. Retrived from https://www.ceeol.com/search/article-detail?id=237060. 